\title{
AlgunOS ASPECTOS RELEVANTES DE LA PRUEBA PERICIAL EN EL PROCESO CIVIL
}

\section{MAITE AgUIRREZABAL GRÜNSTEIN*}

RESUMEN: El presente trabajo tiene por objeto analizar algunos aspectos procesales de relevancia en torno a la prueba pericial en el proceso civil, con especial énfasis en la transformación que ha sufrido la figura del perito y su institucionalización en las reformas procesales chilenas.

\author{
PALABRAS CLAVE: Perito - imparcialidad - testigo - reforma - valora- \\ ción
}

\section{SOME RELEVANTS ASPECTS OF EXPERT EVIDENCE ON CIVIL PROCEEDINGS}

ABSTRACT: This paper aims to examine some relevant procedural aspects about the expert evidence in civil proceedings, with special emphasis on the transformation that the figure of the expert wins and its institutionalization in the procedural reforms in Chile.

KEY WORDS: Expert - impartiality - witness - reform - valuation

\section{1) LA FUNCIÓN DEL PERITAJE EN EL PROCESO CIVIL}

Hoy en día, una apreciación consciente y razonable de los hechos por parte del juzgador es casi imposible sin la aplicación de algún conocimiento técnico o científico. Y la forma más común de acercar este conocimiento al órgano jurisdiccional es a través de la prueba pericial.

Siendo su conocimiento limitado en ciertos ámbitos, el juez requiere cada vez con mayor frecuencia el aporte que en determinadas materias

Licenciada en Ciencias Jurídicas y Sociales por la Universidad de Valparaíso, Abogada, Máster en Derecho de la Empresa por la Universidad de los Andes, Doctora en Derecho por la Universidad de Navarra. Profesora de Derecho Procesal de la Universidad de los Andes. Correo electrónico: maguirrezabal@uandes.cl.

Fecha de recepción: 26 de mayo de 2011.

Fecha de aceptación: 21 de junio de 2011. 
pueda ofrecerle un experto en el tema, sobre algún conocimiento científico o técnico que sirvan para establecer ciertos hechos controvertidos.

De ahí entonces que todos los sistemas procesales contemplen la participación de profesionales o técnicos, conocedores en profundidad de un tema, que pueda servir a un tribunal para establecer una verdad, ya sea por medio de la experiencia o de pruebas técnicas, que determinan un hecho.

Por lo anterior, la prueba pericial se ha convertido en un medio probatorio en donde el juez encuentra en muchas ocasiones su mayor grado de convicción.

Se ha señalado por la doctrina que el peritaje es una actividad realizada por personas "especialmente calificadas, distintas $e$ independientes de las partes y del juez del proceso, por sus conocimientos técnicos, artísticos o cientificos, mediante el cual se suministra al juez argumentos o razones para la formación de su convencimiento respecto de ciertos hechos cuya percepción o entendimiento escapa a las del común de las gentes. Es una prueba ilustrativa sobre alguna materia técnica, que escapa al conocimiento del magistrado"1.

Es que por perito debemos entender aquel tercero, técnicamente idóneo y capaz, llamado a dar opinión y dictamen fundado en un proceso, acerca de la comprobación de hechos cuyo esclarecimiento requiere conocimientos especiales sobre determinada actividad, técnica o arte, el cual es ajeno al juzgador ${ }^{2}$.

La pericia como actividad consiste principalmente en "la aplicación de los conocimiento del experto a un supuesto concreto, emitiendo un parecer, evacuando una opinión o facilitando una información"3.

Se ha discutido en torno a si la prueba pericial debe considerarse como un medio de prueba del que se valen las partes para probar los hechos que afirman, o si bien el perito es un asesor de la administración de justicia, que en su función de tal asesora al juez, quien lo nombra con independencia de la voluntad de las partes, basándose en que la misma es solo un argumento que se le aporta al juzgador con el fin de formarle una opinión más acabada de algún elemento del que no tiene suficiente preparación, además de que quien ha de administrar la justicia no se le

Falcón, Enrique (2003) Tratado de la prueba, t. 2. Buenos Aires: Astrea, p. 4.

Agrega GonzÁlez Pillado, Esther (2000). "La prueba pericial en la nueva Ley de Enjuiciamiento Civil", Revista Xurídica Galega, n² 27, 2000, p. 313, que "perito es, en efecto, la persona que, sin ser parte, emite declaraciones sobre datos que habian adquirido ya de indole procesal en el momento de su observación; estas dos circunstancias son las que diferencian la prueba pericial de la confesión o interrogatorio de las partes, según la terminología que emplea la nueva ley procesal, y de la prueba testifical'.

3 Flores Prada, Ignacio (2005) La prueba pericial de parte en el proceso civil, Valencia: Tirant lo Blanch, p. 128. 
suministra prueba alguna, sino que constituye un elemento de valoración de hechos o de circunstancias ${ }^{4}$.

En este sentido, el peritaje constituiría un auxilio a la administración de justicia, ya que el perito actúa como un intermediario que facilita noticias sobre el estado de una cosa y en donde no se proporciona prueba alguna ${ }^{5}$.

La posición en comento impide configurar la pericia como un medio de prueba, puesto que no tendría por objeto lograr la convicción del juzgador, elemento de la esencia de cualquier medio probatorio.

Esta doctrina resulta minoritaria a la hora de determinar la naturaleza del peritaje, porque lo cierto es que tradicionalmente se ha configurado como un medio de prueba", es decir, un "elemento usado para establecer la verdad acerca de los hechos de la causa" 7 , y que resulta útil para apoyar o confirmar los hechos en que se apoyan las pretensiones de las partes de un modo instrumental, lo que significa que la controversia se produce respecto de ciertos hechos, y lo que debe establecerse en la sentencia es la verdad acerca de los hechos controvertidos.

Por lo mismo, se ha señalado que "lo que distingue a la pericia del resto de los medios de prueba es que la pericial intenta lograr la convicción del tribunal respecto de hechos técnicamente complejos, o sobre aspectos especializados de hechos determinados", y que si se configura "como un método auxiliar del juez, del que pueda servirse de oficio, ya no estamos ante una prueba construida adecuadamente en un proceso presidido por los principios dispositivo y de aportación de parte; estamos más bien ante un instrumento de investigación o averiguación en el marco de un proceso civil inquisitivo"8.

Agrega Flores Prada que "la verdadera singularidad de la pericia reside en el tipo de información que se le suministra al juez, que solo puede

4 Cfr. en este sentido, Garberí Llobregat José (1998) Ley de Enjuicimiento Civil. Interpretación jurisprudencial y legislación complementaria, Barcelona: Bosch, p. 572, quien seńala que "la prueba pericial, atendiendo pues a su función, se caracteriza porque no tiene como finalidad convencer al juzgador de la existencia o no de unos hechos concretos, sino ilustrarle sobre unas materias que, por su carácter especializado, requieren conocimientos concretos de los que, él carece".

5 Criterio esbozado ya por Carnellutti, Francesco (2000) en La prueba Civil. Buenos Aires: Depalma, pp. 73 y ss., en lo que respecta a la configuración del peritaje en el proceso civil italiano, y en que designa al perito como un consultante técnico.

6 En la legislación espańola, hasta mediados de la década de los 70 la doctrina del perito como auxiliar del juez fue acogida por la doctrina espańola, siendo su principal defensor Serra Domínguez, Manuel (1981) "De la prueba de las obligaciones", en Comentarios al Código Civil y a las Compilaciones Forales (dir. Albaladejo García M.), t. XVI, vol. $2^{\circ}$. Madrid: Edersa, pp. 409 y ss., y que postulaba que la función del perito consiste en entregar al juez máximas de validez universal, cumpliendo solo una labor informativa en el proceso, información que no necesariamente se confrontan con las afirmaciones de las partes.

7 Taruffo, Michele (2008) La prueba. Madrid: Marcial Pons, p. 15.

$8 \quad$ Flores Prada (2005) p. 132. 
ser aportada por quienes disponen de los conocimientos técnicos, artísticos o cientificos necesarios", agregando que " $n i$ la información aportada por los peritos puede desligarse de los hechos objeto de prueba en cuanto es necesaria para apreciarlos y valorarlos, ni la finalidad de la pericia difiere de la que persigue el conjunto de la actividad probatoria, que trata de alcanzar el convencimiento del juez sobre la veracidad de las afirmaciones formuladas por las partes" $"$.

Es decir, que en la indagación de los hechos controvertidos, la prueba es un aspecto esencial de la función jurisdiccional, ya se trate de un procedimiento ordinario civil, penal o dentro del proceso arbitral.

En este sentido, se ha señalado que "la llamada prueba pericial es un medio de prueba consistente en la emisión, previamente a la resolución de un asunto concreto, de un dictamen sobre alguna de las materias (aptas para quedar sujetas a la actividad probatoria) que constituyen el objeto del proceso, por una persona ajena al mismo que deberá poseer conocimientos especializados cientificos, artísticos o prácticos, que el juez precisa para valorar mejor las afirmaciones de hechos y circunstancias que constituyen el objeto de la prueba" 10 .

Nuestro Código de Procedimiento Civil así lo recoge en el artículo 341, al contemplarlo como un medio de prueba, y con características propias que la diferencian de la prueba testimonial y de la inspección personal del tribunal.

Como actividad procesal, la pericia está sometida a los límites impuestos a la producción de la prueba. El perito es llamado a informar sobre hechos que constan en el proceso, especialmente cuando se trata de realizar una actividad de deducción o inducción, como es realizar un cálculo indemnizatorio.

Atendiendo al resultado del informe, es posible diferenciar las sigues manifestaciones: a) los que se limitan a dar información sobre las máximas de experiencias, esto es, sobre una determinada ciencia o técnica que el perito conoce como experto, como por ejemplo, un informe químico; b) los que, partiendo de un hecho conocido, proporcionan las causas de un suceso, como por ejemplo, un informe sobre la causa de la ruina de un edificio; c) los que partiendo de un hecho conocido pueden predecir consecuencias futuras, como por ejemplo, un diagnóstico médico sobre la evolución que tendrá el contagio de una enfermedad; y d) los que después de analizar un hecho conocido, pueden deducir ciertas cualidades o antecedentes, como por ejemplo, el que realiza un cálculo matemático ${ }^{11}$.

\footnotetext{
9 Flores Prada (2005) p. 145.

10 Esparza Leibar, Ińaki (2000) El dictamen de peritos en la Ley 1/2000, de Enjuiciamiento Civil. Valencia: Tirant lo Blanch, p. 42.

11 Distinción propuesta por el profesor Alejandro Romero Seguel.
} 


\section{2) LA CONSIDERACIÓN DEL PERITO COMO UN TESTIGO EXPERTO}

En algunos ordenamientos jurídicos, especialmente los comprendidos en el sistema del Common Law, a los peritos se les considera como testigos expertos.

La semejanza que existe entre ambos medios de prueba radica en que ambos realizan declaraciones verbales ante el órgano jurisdiccional, aportando con ello al esclarecimiento de los hechos que se intentan probar.

Las principales diferencias entre peritos y testigos se radican en que los peritos proporcionan conocimientos técnicos como consecuencia de su preparación profesional, no han presenciado el suceso ni tienen referencias de ello, sino que son meros portadores de un conocimiento científico o artístico puestos al servicio de la justicia, en cambio, los testigos dan fe sobre acontecimientos percibidos a través de los órganos sensoriales. El perito a diferencia del testigo, no tiene que transcribir observaciones concretas del suceso objeto de investigación.

Como ya se ha seńalado, en los sistemas del Common Law el perito posee la calidad de testigo experto, aplicándole por lo tanto a la prueba pericial mecanismos procesales similares a los aplicados a la prueba testimonial $^{12}$.

En los Estados Unidos, la prueba pericial por regla general es aportada por la parte, lo que significa que "deciden si presentan o no testigos expertos, los eligen, los preparan para el juicio y les pagan"13, generándose así, en palabras de Taruffo, la figura del perito o testigo experto como un "pistolero a sueldo, dispuesto a servir a la parte que lo convoca"14.

En estos sistemas se han criticado de modo reiterado aspectos tales como los mecanismos de nombramiento del experto, o la falta de control

12 En este sentido, la regla 702 de las Federal Rules of Evidence en EE.UU., modificada en el ańo 2000 para incluir estándares de admisibilidad de la prueba pericial, dispone que "If scientific, technical, or other specialized knowledge will assist the trier of fact to understand the evidence or to determine a fact in issue, a witness qualified as an expert by knowledge, skill, experience, training, or education, may testify there to in the form of an opinion or otherwise, if (1) the testimony is based upon sufficient facts or data, (2) the testimony is the product of reliable principles and methods, and (3) the witness has applied the principles and methods reliably to the facts of the case".

13 Taruffo (2008) p. 90. En los Estados Unidos puede el tribunal designar peritos de oficio, pero es una facultad que casi nunca se utiliza.

14 Taruffo (2008) p. 90. Señala este autor además, que sin perjuicio de que en Inglaterra el principio es el mismo, se dice que el testigo experto tiene como deber principal ayudar al tribunal a llegar a tomar una decisión justa, y que ese deber incluso está por sobre cualquier otra obligación que pueda tener con la parte que lo presenta. Así, seńala la Civil Procedural Rules, en su parte $\mathrm{n}^{\circ} 35$ : "It is the duty of experts to help the court on matters within their expertise. (2) This duty overrides any obligation to the person from whom experts have received instructions or by whom they are paid". 
respecto de la suficiencia de calificación del perito ${ }^{15}$. Lo anterior ha llevado a modificar las reglas procesales en la materia tanto en los Estados Unidos como en Inglaterra.

A ello atiende el que la regla 702 de las Federal Rules of Evidence ${ }^{16}$ haya sufrido algunas modificaciones en torno a la presentación y admisibilidad de la prueba pericial y la prueba científica. Hoy en día incluye criterios específicos para cualificar a los peritos ${ }^{17}$, alejándose del Frye test, proveniente de una decisión de la Corte de Apelaciones del Distrito de Columbia de 1923, que controló por mucho tiempo el estándar de prueba pericial como aquel que se enfocaba en la opinión generalmente aceptada por la comunidad de pares y que luego fue cayendo en el desuso. Más adelante, en 1993, el Tribunal Supremo de Estados Unidos, a través de los fallos pronunciados en los casos Daubert v. Merrell Dow Pharmaceuticals ${ }^{18}$ y Kumbo Tire Co. v. Carmichael ${ }^{19}$, cambia el estándar de confiabilidad, con particular atención a la metodología empleada para la calificación de los testimonios como expertos.

El modelo adoptado por la regla reseñada corresponde a una combinación de los criterios de confiabilidad en el dictamen y el de aceptación por parte de la comunidad científica de los criterios que sirven de base al mismo.

15 En este sentido, Taruffo (2008) pp. 92-93. En el caso de los Estados Unidos, durante el año 2000 se modificó la regla 702 de las Federal Rules of Evidence, estableciendo estándares para la admisibilidad de las pruebas científicas, entre las que destaca por ejemplo el control sobre la fiabilidad del método utilizado por el perito. En Inglaterra se ha producido una situación parecida, en donde se exige como obligación fundamental del perito la de "proceder con verdad, imparcialidad y transparencia ante el tribunal".

16 TARufFo (2008) 92-93.

17 La modificación ya referida, y efectuada en el ańo 2000, tiene su fundamento en el caso de Daubert v. Merrell Dow Pharmaceuticals, en el cual la Corte Suprema de los Estados Unidos estableció ciertos criterios que sirvieran de filtro al momento de seleccionar la prueba científica, tales como la inclusión de metodología, calificaciones e imparcialidad como criterios para cualificar a un testigo como perito. Después de esta decisión judicial se ha modificado sustancialmente la manera en que los jueces evalúan las pruebas científicas. Ahora son los jueces los encargados de decidir si un testimonio científico ha seguido una metodología o razonamiento científico donde se originó la elaboración y promulgación de una norma para la admisión del testimonio de los expertos en tribunales federales. A partir de ese fallo hoy son tres los principales criterios que rigen la admisibilidad del testimonio de los expertos ante un tribunal en los Estados Unidos: La primera, el conocimiento científico, lo que significa que el testimonio debe basarse en "el conocimiento". En segundo lugar, el conocimiento científico tiene que ayudar al órgano jurisdiccional en la comprensión de la evidencia o en la determinación de un hecho controvertido. En tercer lugar, es necesaria una evaluación previa del juez sobre si el razonamiento o la metodología en que se basa la declaración son científicamente válidos y si estos pueden aplicarse correctamente a los hechos en cuestión. Esta evaluación preliminar puede fundarse en criterios tales como la publicación de datos en revistas científicas o la tasa de error real o potencial. 
Ello porque enfatiza el hecho de que el valor probatorio de la prueba dependerá de factores tales como suficiencia, metodología, aplicación, aceptación de la comunidad, calificaciones, parcialidad y discrecionalidad del tribunal para aceptar la prueba y adjudicarle valor probatorio.

En Inglaterra, el sistema es bastante parecido al norteamericano, pero la designación de los peritos, a partir del año 1999, cuenta con importantes limitaciones. En este sentido, las partes solo pueden recurrir a la prueba pericial previa autorización del tribunal, quien además tiene facultades para limitar el número de peritos, las materias sobre las cuales recaerá la prueba pericial y la forma como debe rendirse ${ }^{20}$.

La calificación de la experticia del perito en los sistemas anglosajones se efectúa por "conocimientos, destrezas, experiencias, entrenamiento o educación" 21 , pudiendo el tribunal controlar esta calificación del experto con la finalidad de que la información entregada por el perito sea científica y técnicamente viable.

En cuanto a la forma como puede presentarse el correspondiente informe o dictamen, la regla 702 de las Federal Rules of Evidence, dispone que puede ser como una opinión experta o de otro modo 22 , lo que a juicio de Taruffo significa que "puede suceder que se permita al perito expresar su propio dictamen acerca de los hechos litigiosos, o que se le pida que enuncie algunos conocimientos o principios generales a partir de los cuales el juzgador pueda extraer inferencias relevantes sobre los hechos en litigio" 23.

En lo que respecta al Derecho Continental, un ejemplo cercano a nuestra legislación está constituido por la Ley de Enjuiciamiento Civil española (LEC), que ha innovado en algunos aspectos, estableciendo un

Así, las Civil Procedural Rules, en su n ${ }^{\circ} 35$, disponen que "Expert evidence shall be restricted to that which is reasonably required to resolve the proceedings. No party may call an expert or put in evidence an expert's report without the court's permission. (2) When parties apply for permission they must identify (a) the field in which expert evidence is required; and (b) where practicable, the name of the proposed expert. (3) If permission is granted it shall be in relation only to the expert named or the field identified under paragraph (2)".

21 "a witness qualified as an expert by knowledge, skill, experience, training, or education".

22 "In the form of an opinion or otherwise".

23 Tarufro (2008) p. 92. Dispone además la Rule 703 de las Federal Rules of Procedure, que "The facts or data in the particular case upon which an expert bases an opinion or inference may be those perceived by or made known to the expert at or before the hearing. If of a type reasonably relied upon by experts in the particular field in forming opinions or inferences upon the subject, the facts or data need not be admissible in evidence in order for the opinion or inference to be admitted. Facts or data that are otherwise inadmissible shall not be disclosed to the jury by the proponent of the opinion or inference unless the court determines that their probative value in assisting the jury to evaluate the expert's opinion substantially outweighs their prejudicial effect", lo que en definitiva lleva a concluir que el perito puede emitir opiniones personales sobre los hechos o responder las preguntas que le efectúen el tribunal o las partes, lo que constituye una clara excepción a la prohibición de que los testigos expresen consideraciones personales. 
particular sistema ${ }^{24}$ para rendir la prueba pericial, posibilitando que sean las partes las que aporten en la demanda y contestación de la demanda los dictámenes de peritos designados por ellas ${ }^{25}$, o que sea el juez, a solicitud de parte, el que designe al perito durante el proceso, en los casos que señala el artículo 339 de la $\mathrm{LEC}^{26}$.

También cabe la posibilidad de que el perito se designe de oficio por el tribunal, disponiendo el citado artículo que dicha designación "cuando la pericia sea pertinente en procesos sobre declaración o impugnación de la filiación, paternidad y maternidad, sobre la capacidad de las personas o en procesos matrimoniales".

El artículo 435 de la LEC contempla también una oportunidad para que la prueba pericial se decrete de oficio por el juez, a propósito de las diligencias probatorias finales, disponiendo en el inciso segundo del mencionado artículo que "Excepcionalmente, el tribunal podrá acordar, de oficio o a instancia de parte, que se practiquen de nuevo pruebas sobre hechos relevantes, oportunamente alegados, si los actos de prueba anteriores no hubieran resultado conducentes a causa de circunstancias ya desaparecidas e independientes de la voluntad y diligencia de las partes, siempre que existan motivos

24 No existe acuerdo sobre las bondades del sistema establecido por la LEC. GonZÁLEZ (200o) p. 309, señala que "se ha configurado en términos tales que nos llevan a dudar incluso de su naturaleza y definición como un auténtico medio probatorio, debiendo cuestionarnos quizás si la nueva regulación supone un paso adelante o, por el contrario, lo conveniente hubiera sido optar por un modelo distinto que, superando las deficiencias de la anterior regulación legal, la respetase en lineas generales, en la medida en que quizás de ese modo se evitarian muchas de las incoherencias a que la nueva ley da lugar, y como trataremos de mostrar en el examen que proponemos".

Posibilidad contemplada en el artículo 336 LEC, que dispone que "1. Los dictámenes de que los litigantes dispongan, elaborados por peritos por ellos designados, y que estimen necesarios o convenientes para la defensa de sus derechos, habrán de aportarlos con la demanda o con la contestación, si esta hubiere de realizarse en forma escrita, sin perjuicio de lo dispuesto en el artículo 337 de la presente Ley. 2. Los dictámenes se formularán por escrito, acompañados, en su caso, de los demás documentos, instrumentos o materiales adecuados para exponer el parecer del perito sobre lo que haya sido objeto de la pericia. Si no fuese posible o conveniente aportar estos materiales e instrumentos, el escrito de dictamen contendrá sobre ellos las indicaciones suficientes. Podrán, asimismo, acompañarse al dictamen los documentos que se estimen adecuados para su más acertada valoración. 3. Se entenderá que al demandante le es posible aportar con la demanda dictámenes escritos elaborados por perito por él designado, si no justifica cumplidamente que la defensa de su derecho no ha permitido demorar la interposición de aquella hasta la obtención del dictamen. 4. En los juicios con contestación a la demanda por escrito, el demandado que no pueda aportar dictámenes escritos con aquella contestación a la demanda deberá justificar la imposibilidad de pedirlos y obtenerlos dentro del plazo para contestar".

Dispone el artículo 339 de la LEC, en su parte pertinente que "El demandante o el demandado, aunque no se hallen en el caso del apartado anterior, también podrán solicitar en sus respectivos escritos iniciales o el demandado con la antelación prevista en el párrafo segundo del apartado anterior de este artículo, que se proceda a la designación judicial de perito, si entienden conveniente o necesario para sus intereses la emisión de informe pericial. En tal caso, el Tribunal procederá a la designación, siempre que considere pertinente y útil el dictamen pericial solicitado. Dicho dictamen será a costa de quien lo haya pedido, sin perjuicio de lo que pudiere acordarse en materia de costas". 
fundados para creer que las nuevas actuaciones permitirán adquirir certeza sobre aquellos hechos".

Las reformas procesales incorporadas recientemente en la legislación de nuestro país, y que contemplan el proceso por audiencias, han introducido reformas importantes en materia de prueba pericial, difuminando los límites entre esta y la prueba testimonial, y estableciendo más o menos mecanismos de control para que la prueba se rinda asegurando estándares de imparcialidad y objetividad.

Así, el Código Procesal Penal privilegia la elección del perito por las partes, debiendo además el experto prestar declaración en la audiencia de juicio oral.

Además, en su artículo 314, exige que el informe sea emitido con imparcialidad, estableciendo un control de admisibilidad en que el juez de garantía debe verificar que el perito otorgue suficiente garantía de seriedad y profesionalismo ${ }^{27}$.

Establece también el artículo 318 del mismo Código, que los peritos no podrán ser inhabilitados, pero, agregando en el artículo 317 una importante limitación, esto es, que no podrán ser peritos aquellos que no pueden declarar como testigos en el juicio.

En lo que respecta al procedimiento laboral y al de familia, han contemplado la regulación de la prueba pericial en términos similares, estableciendo el primero que cuando se rinda prueba pericial, el informe deberá encontrarse a disposición de las partes con anterioridad a la audiencia de juicio, y que el juez podrá eximir al perito de concurrir a declarar a esa audiencia, admitiendo el informe como prueba ${ }^{28}$.

En el caso del procedimiento seguido ante los tribunales de familia, los artículos 45 y siguientes de la ley 19.968 repiten el sistema adoptado por el Código Procesal Penal, estableciendo un riguroso control de la prueba pericial, a través de exigencias para las partes, como las de acompańar antecedentes que acrediten la idoneidad del perito ${ }^{29}$ o la etapa previa de admisibilidad de la prueba pericial efectuada por el juez ${ }^{30}$.

27 Artículo 316 del Código Procesal Penal.

28 Artículo 453 del Código del Trabajo. La facultad que posee el juez para eximir al perito de concurrir a prestar declaración debe ser adoptada con el acuerdo de las partes. De no ser así, impediría a nuestro juicio que las partes puedan efectuar observaciones respecto de la persona del perito o de la veracidad del informe o de su declaración, infringiendo con ello su derecho de defensa.

29 Artículo 45 de la Ley 19.968

30 En este sentido, dispone el artículo 47 de la ley 19.968 que "El juez admitirá la prueba pericial cuando, además de los requisitos generales para la admisibilidad de las solicitudes de prueba, considerare que los peritos otorgan suficientes garantias de seriedad y profesionalismo. Con todo, el tribunal podrá limitar el número de peritos, cuando resultaren excesivos o pudieren entorpecer la realización del juicio". 


\section{3) CONTROL DE LA IMPARCIALIDAD DE LA PRUEBA PERICIAL. LA OB- JETIVIDAD DEL INFORME PERICIAL COMO GARANTÍA DE UN DEBI- DO PROCESO}

La imparcialidad es un elemento esencial del debido proceso, que afecta la actitud del juez con las partes, incidiendo específicamente en la forma como ejerce el juez su actividad en los casos concretos que se le someten a su conocimiento.

A través de la garantía de la imparcialidad, se busca que no se desdibujen en el ánimo del juez su carácter de tercero, evitando que concurra a resolver un asunto si existe la mera sospecha de que, por determinadas circunstancias, favorecerá a una de las partes, dejándose llevar por sus vínculos de parentesco, amistad, enemistad, interés en el objeto del proceso o estrechez en el trato con uno de los justiciables, sus representantes o sus abogados.

De lo que se trata, en explicación de Montero Aroca, es evitar en la declaración del Derecho Objetivo todo designio anticipado o la prevención para no cumplir con rectitud la función jurisdiccional ${ }^{31}$.

No debe ser confundida con la independencia, ya que esta última se refiere a una cuestión previa, de organización, a través de la cual se pretende liberar al juez de toda subordinación que no sea la que el juez deba estrictamente al Derecho.

La imparcialidad "no es una característica abstracta de los jueces y magistrados, sino que hace referencia concreta a cada caso que se somete a su decisión. Por ello la ley tiene que establecer una lista cerrada de situaciones objetivas que conviertan a los jueces en sospechosos. La mera concurrencia de una de estas situaciones (...) obliga al juez a abstenerse y permite a la parte recusarlo..." 32 .

La exigencia de un actuar imparcial se hace extensiva a todo aquel que de una u otra forma intervenga en el proceso, es decir, la regla se hace extensiva a los testigos, a los peritos, etc., quienes se verán afectados por causales de inhabilidad en el evento que dicho requisito falte.

Ello porque, la finalidad de esta prueba, como la del resto de las previstas en la Ley, consiste en acreditar los hechos que fundamentan las pretensiones de las partes en el proceso, con la particularidad, de que el objeto de la prueba pericial son hechos que no son del común saber de las partes o del juez, de modo que el perito, mediante su informe, proporciona al tribunal los conocimientos técnicos necesarios para la valoración de los hechos objeto de la controversia.

31 Cfr. Montero Aroca, Juan (1999) Sobre la Imparcialidad del Juez y la incompatibilidad de funciones procesales. Valencia: Tirant lo Blanch, p. 332.

32 Núñez OJeda, Raúl (1998) "La imparcialidad objetiva del juzgador penal y el principio acusatorio (el caso espańol)”, en Revista de Derecho y Jurisprudencia, T.XCV, nº 1, p.4. 
Es decir, cuando el perito actúa conforme con los criterios válidos y vigentes en la disciplina que se trate y los aporta al tribunal diciendo la verdad, se garantiza el mínimo necesario de imparcialidad científica, objetiva, que debe concurrir en el trabajo de examen y emisión del dictamen pericial.

Carnelutti hacía alusión a la importancia que revestía el hecho de distinguirlos estableciendo que el testigo solo relata, refiere, narra hechos; en tanto que el perito expresa juicios debido a algún conocimiento propio de su profesión y que el juzgador desconoce, considerando además que "el perito es un sujeto, el testigo es un objeto del proceso; el uno y el otro proporcionan al juez noticias, pero el origen de estas es diverso: la ciencia del perito se forma en el proceso, y la ciencia del testigo fuera del proceso, en el sentido de que el primero actúa para lograrla en cumplimiento de un encargo del juez $y$ el segundo sin encargo alguno"33.

Ello porque el testigo declara sobre los hechos controvertidos respecto de los cuales ha tomado conocimiento, ya sea de modo presencial o de oídas, mientras que el perito aporta un conocimiento científico o técnico que se requiere para valorar de mejor manera esos mismos hechos controvertidos.

La labor del perito, independientemente de cuál sea su calificación jurídica, está orientada a colaborar con el tribunal en el esclarecimiento de los hechos, mientras que el testigo será siempre un tercero imparcial que declara sobre ciertos hechos porque los conoce.

En base a lo anterior nuestra legislación procesal civil reglamenta separadamente, y de modo distinto, la prueba pericial y la prueba testimonial.

La prueba pericial se encuentra regulada de modo detallado en los artículos 409 y siguientes del Código de Procedimiento Civil, en donde se regula el sistema de nombramiento de los peritos, aceptación y juramento de su cargo y la forma en que deben evacuar el informe pericial.

Así, la iniciativa para rendir la prueba pericial corresponde a las partes, quienes deberán solicitar la designación de perito dentro del término probatorio. También se ha previsto la posibilidad de que sea decretada de oficio por el juez en cualquier estado del proceso o bien como medida para mejor resolver, debiendo oírse en todos aquellos casos en que la ley lo disponga o cuando exista la necesidad de consultar opiniones periciales $^{34}$.

33 Carnelutti Francesco, citado por Pallares Eduardo (1990) Diccionario de Derecho Procesal Civil. México: Porrúa, p. 565.

34 Artículo 409 del Código de Procedimiento Civil, agregando el artículo 411 que también podrá oírse informe de peritos cuando existan puntos de hecho para cuya apreciación se requieran conocimientos especiales de alguna ciencia o arte, o sobre puntos de derecho de alguna legislación extranjera. 
Debe citarse a una audiencia para proceder a la designación del perito, el que será nombrado de común acuerdo por las partes y a falta de acuerdo por el tribunal, quien deberá elegirlo de las listas a las que se refiere el artículo 417.

Los peritos deben aceptar el cargo y jurar desempeńarlo con fidelidad, practicando el reconocimiento y emitiendo el correspondiente informe pericial ${ }^{35}$, sin que luego deban declarar en una audiencia posterior sobre dicho dictamen, y teniendo las partes la posibilidad de formular observaciones a este último, y apreciándose el valor probatorio del dictamen en conformidad con las reglas de la sana crítica.

En la actualidad, la forma como nuestra legislación procesal civil protege la imparcialidad de la prueba pericial, es haciendo aplicable al perito las normas sobre inhabilidades de los testigos.

Así, señala el artículo 417 del Código de Procedimiento Civil que "el perito que acepte el cargo, deberá declararlo así, jurando desempeñarlo con fidelidad", mientras que el artículo 413 del citado cuerpo legal, dispone expresamente en su numeral $1^{\circ}$, que no podrán ser peritos aquellos que sean inhábiles para declarar como testigos en el juicio ${ }^{36}$.

A su vez, el artículo $358 n^{\circ} 6$ del Código de Procedimiento Civil establece que son inhábiles para declarar como testigos, "los que a juicio del tribunal carezcan de la imparcialidad necesaria para declarar por tener en el pleito interés directo o indirecto", entendiendo la jurisprudencia, de modo reiterado, que este interés debe ser de carácter patrimonial, lo que en el caso concreto que se comenta, ocurriría.

Nuestra jurisprudencia ha ratificado este criterio señalando que de acuerdo a lo establecido en los artículos 411 Nos 1º, 13 No 2, 414, 419 y 421 del Código de Procedimiento Civil, es de la esencia de la prueba de peritos que en "la ilustración de las cuestiones que debe resolver el Juez", el perito, se refiera y deba ceńirse necesariamente a la "apreciación" de "puntos de hecho" y de aquellas "circunstancias" pertinentes en que se necesiten "conocimientos especiales de una ciencia o arte", siendo precisamente por ello que en la designación de todo perito habrá de estarse al "título

35 Artículos 419 y siguientes del Código de Procedimiento Civil.

36 La LEC establece también un sistema de tachas y recusaciones cuya aplicación depende de la forma como haya sido designado por el tribunal. En este sentido, dispone el artículo 343 LEC, que "Solo podrán ser objeto de recusación los peritos designados judicialmente. En cambio, los peritos no recusables podrán ser objeto de tacha cuando concurra en ellos alguna de las siguientes circunstancias: 1. Ser cónyuge o pariente por consanguinidad o afinidad, dentro del cuarto grado civil de una de las partes o de sus abogados o procuradores. 2. Tener interés directo $o$ indirecto en el asunto o en otro semejante. 3. Estar o haber estado en situación de dependencia o de comunidad o contraposición de intereses con alguna de las partes o con sus abogados o procuradores. 4. Amistad intima o enemistad con cualquiera de las partes o sus procuradores o abogados. 5. Cualquier otra circunstancia, debidamente acreditada, que les haga desmerecer en el concepto profesional'. 
profesional" que tuviere o, en su defecto y en su caso, a la "calidad" o "aptitudes" que "deben tener" los referidos peritos en relación al "punto o puntos materia del informe", agregando que "carecerá de valor en su dictamen todo aquello que escape a la "ciencia o arte" que el perito profese, siendo consiguientemente también ajeno a su natural órbita de competencia todo juicio de valor y con mayor razón toda calificación juridica que saliéndose de ese ámbito emita el perito al cumplir su encargo" 37.

También ha declarado que la existencia del contrato de honorarios en el que se pacta la remuneración del perito de acuerdo con los montos que dictamine el experto en su informe, afecta de modo manifiesto su imparcialidad, por cuanto, y respecto del informe, "el propio perito ha reconocido que al momento de su confección tenía un interés patrimonial en la resulta de este juicio, elemento que le hace perder la imparcialidad que debe tener al momento de ejecutar la labor que le encomendara el tribunal, sobre todo si se tiene presente que su labor es de auxiliar en la administración de justicia"38.

Sin embargo, el proyecto de ley que busca aprobar un nuevo Código Procesal Civil ${ }^{39}$ no ha tomado en cuenta estos criterios más conservadores al momento de regular la prueba pericial.

37 Considerando segundo del fallo de fecha 4 de agosto de 1998, pronunciado por la Corte de Apelaciones de Santiago en causa caratulada "Arcaya y López S.A. con Tecnología del Aluminio Ltda.".

38 En la causa sobre constitución de servidumbre minera caratulada "Angloamerican Sur S.A. con Constructora Daves Limitada", Rol No 33.117-2008, seguida ante el 240 Juzgado Civil de Santiago, la parte demandante recurre de apelación la sentencia definitiva, recurso que rola con el no 2166-2010. En primera instancia se ordenó una prueba pericial, y el informe solicitado en la materia, concluyó que la afección patrimonial de la demandada, producida por la constitución de la servidumbre en el inmueble. La sentencia definitiva de primera instancia condenó a la demandante al pago de una indemnización ascendente a la suma indicada por el perito en su dictamen. Con fecha con fecha 11 de diciembre de 2009, ante el juez de primera instancia que conoció del litigio, el perito judicial designado promovió un cobro incidental de honorarios que hizo pública la existencia de un contrato de honorarios cuya cuantía se estipuló a las resultas pecuniarias del juicio, según el siguiente detalle: "CUARTO: Ante el evento que a la empresa Constructora le sea favorable la demanda, por sobre $\$ 250.000 .000$. (doscientos cincuenta millones), pagará a don xxxx la suma de $\$ 10.000 .000$ extra, hasta completar los $\$ 15.000 .000$ (quince millones) como suma total y sin impuestos. Ellos serán pagados a más tardar 5 días posterior a la resolución del Tribunal". La Corte de Apelaciones de Santiago, con fecha 10 de marzo de 2011, conociendo del recurso de apelación interpuesto por la demandante, confirma el fallo de primera instancia pero con declaración de que el monto de la indemnización que deberá pagarse al demandante es significativamente menor que la ordenada pagar por el fallo recurrido, fundando el fallo en el interés del perito. Por lo anterior, la Corte de Apelaciones resta cualquier mérito probatorio al informe pericial, y fija la indemnización de perjuicios correspondiente en consideración a las características del inmueble, la superficie total afectada con la constitución de la servidumbre, el total del inmueble, a su destino, y a si se pueden o no desarrollar actividades económicas en este. Mensaje $\mathrm{n}^{\circ}$ 398-357, de fecha 19 de mayo de 2009. 
El artículo 289 del Proyecto en su actual redacción, dispone que "Las partes podrán recabar informes elaborados por peritos de su confianza y solicitar que estos sean citados a declarar a la audiencia de juicio, acompañando los antecedentes que acreditaren la idoneidad técnica del perito y su eventual relación con las partes del juicio y del tribunal", agregando que "procederá la prueba pericial en los casos determinados por la ley y siempre que, para apreciar algún hecho o circunstancia relevante para la causa, fueren necesarios $o$ convenientes conocimientos especiales de una ciencia, arte u oficio".

Agrega además el artículo 291, que los honorarios y gastos del perito corresponderán a la parte que lo presente, disponiendo el artículo 292 que estos no podrán ser inhabilitados, sin perjuicio de poder dirigírseles en la audiencia de juicio preguntas orientadas a determinar su relación con las partes o el tribunal ${ }^{40}$.

Así, el artículo 300 del Proyecto en su actual redacción, dispone que "Las partes podrán recabar informes elaborados por peritos de su confianza y solicitar que estos sean citados a declarar a la audiencia de juicio, acompañando los antecedentes que acreditaren la idoneidad técnica del perito y su eventual relación con las partes del juicio y del tribunal", agregando que "el tribunal solo podrá ordenar un peritaje cuando no haya sido ofrecido por alguna de las partes..." 41.

Agrega además el artículo 303, que los honorarios y gastos del perito corresponderán a la parte que lo presente, y el artículo 304 dispone que los peritos no podrán ser inhabilitados, sin perjuicio de poder dirigírseles en la audiencia de juicio preguntas orientadas a determinar su relación con las partes o el tribunal.

Como podemos observar, el proyecto de reforma procesal civil adopta la misma estructura que a propósito de la prueba pericial contempla el Código Procesal Penal, pero con la salvedad de que este último resulta más riguroso que el primero en cuanto al control de la objetividad e imparcialidad de la prueba pericial, puesto que en el ámbito procesal civil no se ha previsto un control de admisibilidad de la prueba pericial por parte del juez con el objeto de garantizar su seriedad, ni tampoco la po-

40 Creemos que en definitiva, el proyecto dejaría de lado el sistema de inhabilidades que actualmente regulan la prueba pericial, y la reforma introducida por la ley 20.192 , de 26 de junio de 2007, que modifica el artículo 416 del Código de Procedimiento Civil, estableciendo que "Cuando el nombramiento se haga por el tribunal, lo hará de entre los peritos de la especialidad requerida que figuren en las listas a que se refiere el articulo siguiente y la designación se pondrá en conocimiento de las partes para que dentro de tercero día deduzcan oposición, si tienen alguna incapacidad legal que reclamar contra el nombrado. Vencido este plazo sin que se formule oposición, se entenderá aceptado el nombramiento".

41 Tendencia opuesta a la que actualmente se sigue en el sistema anglosajón, en el que, tal como hemos seńalado, el juez ejerce un control importante sobre la admisibilidad y forma de rendirla la prueba pericial. 
sibilidad de inhabilitar a los peritos que no puedan declarar como testi$\operatorname{gos}^{42}$.

\section{4) VALORACIÓN DE LA PRUEBA PERICIAL EN EL PROCESO CIVIL}

La prueba pericial se enmarca, como se ha señalado, dentro de lo que se denomina la prueba científica, la que goza de un alto poder de fiabilidad.

Por regla general, la valoración que el juez efectúa del informe de peritos se realiza conforme a las reglas de la sana crítica ${ }^{43}$, y sin que por ella esta prueba deba prevalecer sobre el resto de las pruebas allegadas al proceso, valorándose la misma en su conjunto ${ }^{44}$.

Señala Taruffo que, a propósito de la prueba científica surge "la tradicional paradoja del juzgador como peritum peritorum. Por un lado, se presupone que el juez recurre al cientifico precisamente porque no tiene los conocimientos cientificos necesarios para decidir sobre los hechos del caso; pero

Artículo 316 del Código Procesal Penal.

43 Son múltiples las definiciones que de sana crítica podemos encontrar. Alsina, Hugo (1956) Tratado Teórico Práctico de Derecho Procesal Civil y Comercial. Buenos Aires: Ediar, vol. I, p. 127, señala que "Las reglas de la sana crítica, no son otras que las que prescribe la lógica $y$ derivan de la experiencia, las primeras con carácter permanente y las segundas, variables en el tiempo y en el espacio", agregando Couture, Eduardo (1948) Estudios de Derecho Procesal Civil. Buenos Aires: Depalma, p.195, que corresponden a "las reglas del correcto entendimiento humano; contingentes y variables con relación a la experiencia del tiempo y del lugar; pero estables y permanentes en cuanto a los principios lógicos en que debe apoyarse la sentencia". Nuestra jurisprudencia ha señalado también, en reiteradas oportunidades, que a pesar de que la ley no entrega un concepto de lo que es "sana crítica", aporta algunos parámetros que deben tenerse en cuenta a la hora de efectuar el análisis y la correspondiente ponderación de los diversos medios probatorios legalmente incorporados al juicio. Puede decirse en términos generales, que la sana crítica "es un método razonado y reflexivo de analizar el material probatorio acompañado al juicio, análisis que debe enmarcarse dentro de los limites de la lógica formal, las máximas de la experiencia y los conocimientos cientificamente afianzados", distinguiendo además entre la sana crítica y la libre convicción, siendo este último "aquel modo de razonar que no se apoya necesariamente en la prueba que el proceso exhibe al juez, ni en medios de información que pueden ser fiscalizado por las partes".

44 Así se desprende del artículo 170 del Código de Procedimiento Civil, que en su numeral $4^{\circ}$ exige al juzgador la exposición de los fundamentos de hecho o de derecho en las que se funda el fallo, y del artículo 160 del citado código, que dispone que las sentencias deben pronunciarse conforme al mérito del proceso. Nuestra jurisprudencia reitera este criterio, cuando seńala que "la apreciación de parte de la prueba para fundar la relación laboral ha trasgredido las reglas de la lógica, desde el momento en que no se han considerado los demás elementos planteados por la demandada que demostraban lo contrario, o por lo menos, el Tribunal no se ha hecho cargo de tales antecedentes, para poder establecer un criterio que no pueda ser rebatido. En concreto, lo que se objeta al Tribunal a través de esta causal es que haya concluido lo que concluyó sin tomar en consideración toda la prueba o sin hacer las relaciones lógicas y necesarias para vincular tales pruebas, de manera de acoger unas en desmedro de otras, pues ellas eran contradictorias" (Corte de Apelaciones de Valparaíso, en fallo de fecha 28 de febrero de 2011, rol n 41-2011) 
por otro, se exige que el mismo juez sea capaz de valorar la fiabilidad de los resultados de la prueba cientifica y de atribuirles el peso probatorio que, sobre la base en su convicción discrecional, considere adecuado" ${ }^{45}$, agregando que "se pide que el juez motive especificamente su resolución sobre el resultado de la prueba pericial, sobre todo cuando su valoración difiere de la del perito".

Se trataría por tanto de una suerte de discrecionalidad judicial guiada por las reglas de la ciencia y de la lógica, estando siempre obligado a la motivación racional de los criterios que adopte ${ }^{46}$.

En este sentido, resultan importantes las palabras de Devis, cuando señala que "la doctrina moderna está de acuerdo en esta libertad, que consideramos indispensable para que el perito no usurpe la función jurisdiccional del juez y para que este pueda controlar cabalmente si el dictamen cumple o no los requisitos para su existencia, validez y eficacia probatoria. Quienes defienden la libre valoración por el juez de las pruebas en general, obviamente la reclaman para la peritación; quienes estiman que no se trata de un verdadero medio de prueba, sino de un acto auxiliar para ilustrar al juez en materias técnicas, artísticas o cientificas, con mayor razón consideran que las conclusiones del dictamen nunca vinculan al juzgador" 47.

Agrega Taruffo que puede suceder "que el sentido común no comprenda las nociones las nociones suficientes para permitir al juez valorar adecuadamente las pruebas de la forma que se ha señalado. La única consecuencia que se puede extraer de ello es que la valoración de la prueba cientifica es una actividad que trasciende el sentido común, requiriendo del juez la capacidad de conocer la ciencia para realizar apropiadamente su función judicial. Claro está que sería absurdo pretender que el juez sea omnisciente, pero parece razonable, en la sociedad actual, que el juez disponga de una formación epistemológica básica que le permita realizar una adecuada valoración critica de la validez y fiabilidad de las pruebas cientificas" 48 .

Como bien hemos podido apreciar, el medio de prueba pericial, antes poco conocido o difundido, va adquiriendo paulatinamente fuerza y se van incorporando al igual que el resto de las probanzas al proceso civil como un medio de prueba más, que le ilustran (los peritos) en buena medida a los jueces de elementos que estos desconocen, para lograr una

TARuffo (2008) p. 293. Agrega este autor que en todo caso, la paradoja es tan solo aparente, puesto que cuando el juez realiza una valoración de la prueba científica no se pretende que se transforme en un científico, sino que lo que se exige "es que el juez sea capaz de valorar si está en el ámbito de una forma de conocimiento dotada de dignidad y validez cientifica, y si los métodos de investigación y control tipicos de esa ciencia han sido correctamente aplicados en el caso particular que debe juzgar". En este sentido, Taruffo, Michele (2009) La prueba. Articulos y conferencias. Santiago: Editorial Metropolitana, pp. 87 y ss. 347.

48

TARUfFo (2008) p. 295. 
apreciación más acercada al objeto del dictamen, aunque el tribunal tiene la facultad de apartarse del criterio expuesto en el dictamen pericial, siempre y cuando pueda fundamentar correctamente el punto de vista propio.

\section{Bibliografía Citada}

- Alsina, Hugo (1956). Tratado Teórico Práctico de Derecho Procesal Civil y Comercial. Buenos Aires: Ediar.

- Carnellutti, Francesco (2000). La prueba Civil. Buenos Aires: Depalma.

- Couture, Eduardo (1948). Estudios de Derecho Procesal Civil. Buenos Aires: Depalma.

- Devis Echandía, Hernando (2002). Teoría general de la prueba judicial. Bogotá: Temis.

- Esparza Leibar, Ińaki (2000). El dictamen de peritos en la Ley 1/2000, de Enjuiciamiento Civil. Valencia: Tirant lo Blanch.

- Falcón, Enrique (2003). Tratado de la prueba, t. 2. Buenos Aires: Astrea.

- Flores Prada, Ignacio (2005). La prueba pericial de parte en el proceso civil. Valencia: Tirant Lo Blanch.

- Garberí Llobregat José (1998). Ley de Enjuicimiento Civil. Interpretación jurisprudencial y legislación complementaria. Barcelona: Bosch.

- González Pillado, Esther (2000). "La prueba pericial en la nueva Ley de Enjuiciamiento Civil”, Revista Xurídica Galega, n² 27, 2000, PP. 307-344.

- Montero Aroca, Juan (1999). Sobre la Imparcialidad del Juez y la incompatibilidad de funciones procesales. Valencia: Tirant lo Blanch.

- Núñez OJeda, Raúl (1998). "La imparcialidad objetiva del juzgador penal y el principio acusatorio (el caso espańol)”, en RDJ, T.XCV, $\mathrm{n}^{\circ} 1,1998$, PP. 1-36.

- Pallares Eduardo (1990). Diccionario de Derecho Procesal Civil. México: Porrúa.

- Serra Domínguez, Manuel (1981). "De la prueba de las obligaciones", en Comentarios al Código Civil y a las Compilaciones Forales, (dir. Albaladejo García M.), t. XVI, vol. $2^{\circ}$. Madrid: Edersa.

- Taruffo, Michele (2008). La prueba. Madrid: Marcial Pons.

- Taruffo, Michele (2009). La prueba. Artículos y conferencias. Santiago: Editorial Metropolitana. 